\title{
A Case Series of Various Swelling of Fingers in Adults
}

\author{
S. K. Venkatesh Gupta, Srujith Kommera \\ Department of Orthopaedics, Mamata Medical College, Khammam, India \\ Email: veegee_47@yahoo.c0.in, kommerasrujith@gmail.com
}

Received 8 October 2014; revised 24 November 2014; accepted 8 December 2014

Copyright (C) 2014 by authors and Scientific Research Publishing Inc.

This work is licensed under the Creative Commons Attribution International License (CC BY).

http://creativecommons.org/licenses/by/4.0/

(c) (i)

\section{Abstract}

Patients commonly present to their general practitioner with swellings of the hand. These include a variety of diagnoses with certain lesions (for example, ganglion) being more common than others. Some may even be familiar as they are often site-specific. This article aims to provide general practitioners with clear and concise information regarding swellings to be ruled out before suspecting giant cell tumor of tendon sheath. Swellings of the hand are commonly encountered in a general practice with different diagnosis. They may arise from any tissue in the hand including skin, subcutaneous fat, muscle, nerves, vessels, tendon, bone and cartilage. Fortunately, most are benign, asymptomatic and may not require surgical intervention. Ganglions, epidermoid inclusion cysts, giant cell tumours of the tendon sheath, and swellings associated with arthropathy comprise the majority of lesion. This study includes 16 cases which are presented with similar history and presentation of finger swellings as that of giant cell tumor tendon sheath but the final diagnosis has varied.

\section{Keywords}

Differential Diagnosis Giant Cell Tumor of Tendon Sheath, Inclusion Epidermoid Cyst, Ganglion, Lipoma, Heberden's Nodes and Bouchard's Nodes

\section{Introduction}

There are different swellings of fingers to be ruled out before suspecting giant cell tumor of tendon sheath.

Giant cell tumor of the tendon sheath (GCTTS) is a benign tumor, presenting as the second most common mass of the hand after ganglion cysts. It was first described by Chassaignac in 1852 as fibrous xanthoma. The large range of nomenclature indicates disagreement as to the etiology of giant cell tumors. The prevailing diver- 
gence is between a neoplastic and inflammatory origin of the tumor, with multiple studies presenting evidence for each [1].

Despite the undetermined etiology, the clinical presentation, diagnosis, and surgical treatment are described and compared with similar type of swellings having similar clinical presentation.

GCTTS most commonly presents in fingers mostly in the fourth and fifth decades of life, with women affected more commonly than men [2].

Grossly, GCTTS is a multilobular and generally well-circumscribed tumor. It may be partially or completely encapsulated and may have extensions and/or satellite lesions connected by as little as a few strands of fibrous tissue. Coloration varies from gray to yellow-orange with some brownish areas. Giant cell tumor of the tendon sheath is most commonly found at the level of distal interphalangeal (DIP) joint and the proximal phalanx [1]. Giant cell tumor of the tendon sheath most commonly presents as a firm, nontender, not fluctuant nodule in a digit of the hand. The tumor is predominantly palmer. Because of the slow-growing nature of the tumor, patients present an average of 6 months to 2.5 years after the initial onset of symptoms.

Diagnosis of GCTTS is largely made by clinical examination but the other common swellings of fingers to be ruled out are:

Accordingly to frequency of their occurrence are [3]:

1) Ganglion

2) Epidermoid cyst

3) Mucous cysts

4) Glomus tumor

5) Rheumatoid nodules

6) Enchondroma

7) Tophaceous gout

8) Lipoma

\section{Materials and Methods}

Between May 2012 and May 2014 a total of 16 middle aged patients between 30 to 50 years presented with swelling over volar aspect of fingers at Mamata General and Super Specialty Hospital. There were 10 female and 6 male patients included in this study. All the patients reported with long history which is of more than 1 year duration and there was no history of any trauma and there are no similar types of swellings anywhere in the body. All the patients had swellings over flexor aspect of fingers which are insidious in onset and gradually progressing. Of 16 cases; patients presented with swellings over right hand (dominant hand) were 12 and 4 cases on left hand. 12 out of 16 cases presented with pain of less than 6 months duration others had only presented with pain and restriction of movements due to swelling. There were no complaints of any paresthesia or numbness over fingers. There was no history of any constitutional symptoms in any of the patients.

Clinically —all the patients presented with well defined, 10 had globular swellings (Figure 1(a) and Figure 1(b)) 6 cases had nodular swellings (Figure 1(c)). Of 16 cases in series 12 cases had tender swellings and 3 cases were non tender but had restriction of movements. All the swellings were firm to cystic in consistency of which 14 were firm and 2 were cystic.

In all the cases in the series X-rays were taken indicate a soft tissue mass in all the cases, there were no bony involvement noted.

FNAC was performed in all the cases of which 8 cases where microscopically suggesting of Giant cell tumor, 4 cases of epidermal cysts, 3 cases of ganglion and 1 case suggesting lipoma.

Further, all cases were operated under wrist block and finger tourniquet with elastic band control. Special care was taken to excise the tumor in total, retaining the capsule, with margin of normal tissue. The operating field is searched for presence of satellite lesions or daughter cysts. The entire specimen was then subjected to Histopathological examination, and the margins were observed for clearance.

Intraoperatively—Six cases were single nodule surrounded by thick pseudo capsule (Figure 2(a)), six were single nodule within a thin capsule (Figure 2(b)). Three lesions were found to be multi-lobulated surrounded by a common capsule (Figure 2(b)). Another lesion found was to be nodular like lesions without a pseudo-capsule.

Histopathaologically the diagnosis was confirmed as that of FNAC using hematoxylin and eosin stains (Figure 3). 


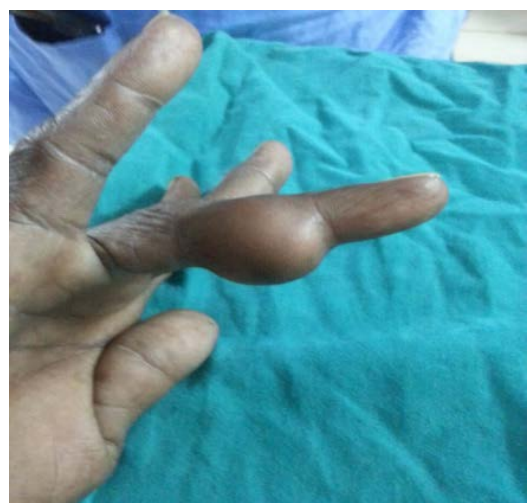

(a)

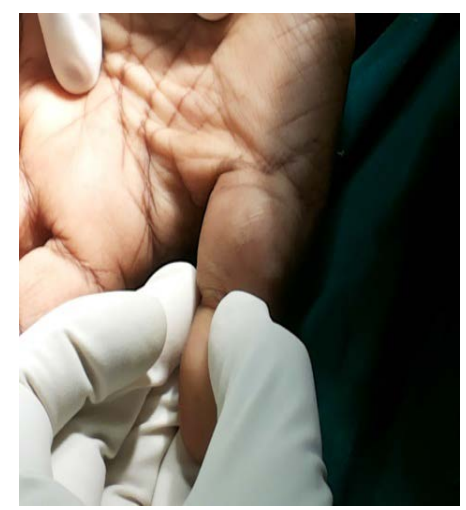

(b)

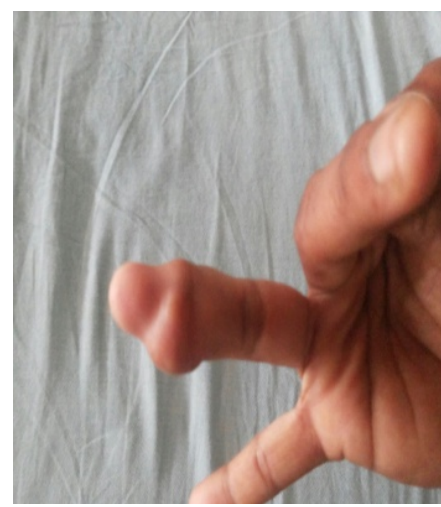

(c)

Figure 1. (a) Epidermiod inclusion cyst; (b) GCTTS; (c) Lipoma.

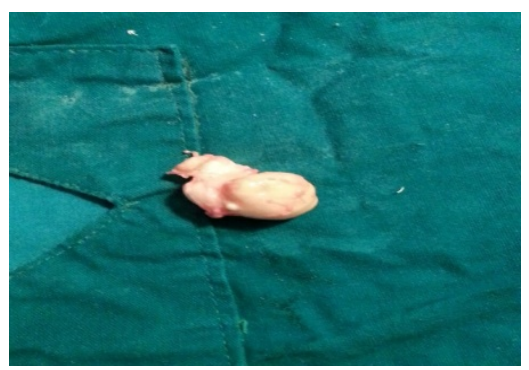

(a)

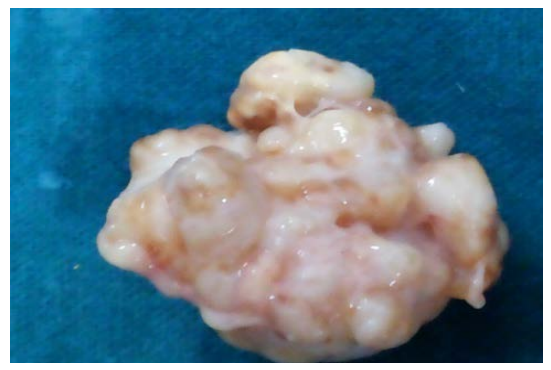

(b)

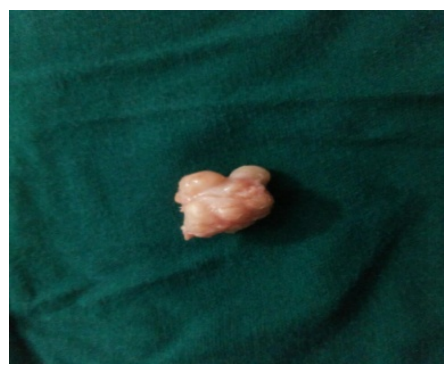

(c)

Figure 2. (a) Epidermiod inclusion cyst, size of swelling-3 $32 \mathrm{~cm}$; (b) GCTTS, $4 \times 3 \mathrm{~cm}$; (c) Lipoma, $2 \times 2 \mathrm{~cm}$.

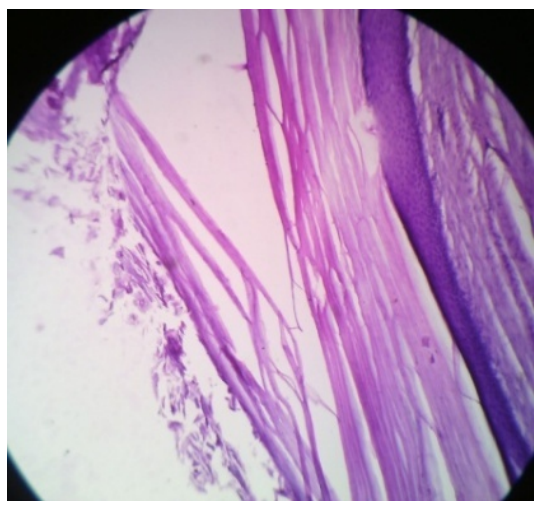

(a)

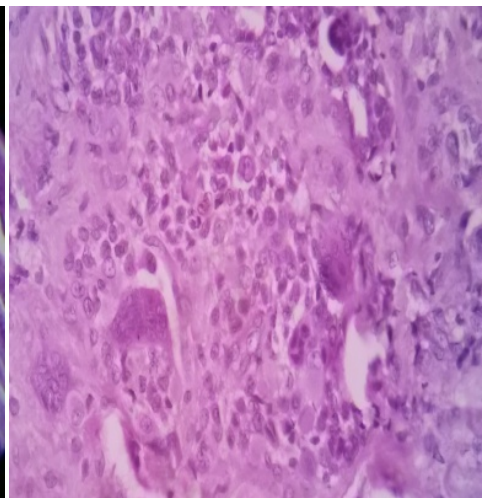

(b)

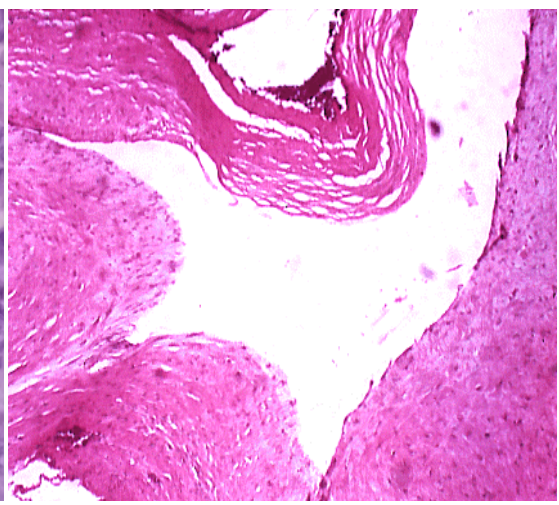

(c)

Figure 3. (a) Epidermiod inclusion cyst; (b) GCTTS; (c) Lipoma.

\section{Results}

A total of 16 patients with 10 females (62.5\%) and 6 (37.5\%) males within 30 to 50 years age group with mean age of (37.75) presented clinically with similar type of swellings on volar aspect of fingers (Figure 4).

Patients most often presented with a tender, slow-growing swelling with no history of trauma and no associated numbness or tingling. Tenderness was noted in $80 \%$ of patients. The affected hand was right hand (75\%) which is dominant in hand. The swelling was fixed to underlying tissue in 13 (81.25\%) and mobile in 3 (18.75\%) cases. Most of swellings were firm in consistency (87.5\%). 56\% cases of patients had restriction of movements due to swelling (Table 1 ).

Finally out of 16 patients in the series 8 (50\%) cases were diagnosed as giant cell tumor of tendon sheath, 4 (25\%) cases as epidermoid cyst, 3 (18.75\%) cases as ganglion and $1(6.25 \%)$ as lipoma. 
Table 1. Demographic details, clinical features and final diagnosis of patients.

\begin{tabular}{|c|c|c|c|c|c|c|c|c|c|c|}
\hline S.NO & Age & Sex & Side & Finger & $\begin{array}{l}\text { Type of } \\
\text { swelling }\end{array}$ & Tender & $\begin{array}{l}\text { Firm/ } \\
\text { Cystic }\end{array}$ & $\begin{array}{l}\text { Mobile/ } \\
\text { Fixed }\end{array}$ & $\begin{array}{c}\text { Restriction of } \\
\text { movements }\end{array}$ & Diagnosis \\
\hline 1. & 32 & $\mathrm{~F}$ & $\mathrm{R}$ & 5 & Globular & + & Firm & Fixed & + & Giant cell tumor of tendon sheath \\
\hline 2 & 45 & M & $\mathrm{R}$ & 4 & Nodular & + & Firm & Fixed & - & Giant cell tumor of tendon sheath \\
\hline 3 & 50 & $\mathrm{M}$ & $\mathrm{L}$ & 2 & Globular & + & Cystic & Fixed & + & Ganglion \\
\hline 4 & 46 & $\mathrm{~F}$ & $\mathrm{~L}$ & 3 & Nodular & + & Firm & Mobile & - & Epidermoid cyst \\
\hline 5 & 41 & $\mathrm{M}$ & $\mathrm{R}$ & 2 & Nodular & + & Firm & Fixed & + & Giant cell tumor of tendon sheath \\
\hline 6 & 30 & $\mathrm{~F}$ & $\mathrm{R}$ & 1 & Globular & + & Firm & Fixed & - & Giant cell tumor of tendon sheath \\
\hline 7 & 33 & M & $\mathrm{R}$ & 2 & Nodular & + & Firm & Fixed & + & Giant cell tumor of tendon sheath \\
\hline 8 & 31 & $\mathrm{M}$ & $\mathrm{R}$ & 5 & Nodular & - & Firm & Fixed & + & Epidermoid cyst \\
\hline 9 & 35 & $\mathrm{~F}$ & $\mathrm{R}$ & 4 & Nodular & + & Firm & Fixed & - & Giant cell tumor of tendon sheath \\
\hline 10 & 43 & $\mathrm{~F}$ & $\mathrm{~L}$ & 3 & Globular & - & Firm & Mobile & + & Ganglion \\
\hline 11 & 36 & M & $\mathrm{R}$ & 2 & Nodular & + & Firm & Fixed & - & Epidermoid cyst \\
\hline 12 & 31 & $\mathrm{~F}$ & $\mathrm{R}$ & 5 & Globular & + & Cystic & Fixed & - & Ganglion \\
\hline 13 & 41 & $\mathrm{~F}$ & $\mathrm{R}$ & 3 & Nodular & + & Firm & Fixed & + & Giant cell tumor of tendon sheath \\
\hline 14 & 49 & $\mathrm{~F}$ & $\mathrm{~L}$ & 4 & Nodular & + & Firm & Fixed & - & Epidermoid cyst \\
\hline 15 & 30 & $\mathrm{~F}$ & $\mathrm{R}$ & 2 & Nodular & + & Firm & Fixed & + & Giant cell tumor of tendon sheath \\
\hline 16 & 31 & $\mathrm{~F}$ & $\mathrm{R}$ & 3 & Globular & - & Firm & Mobile & + & Lipoma \\
\hline
\end{tabular}

F-female; M-male; R—right; L—left; + present; - absent.

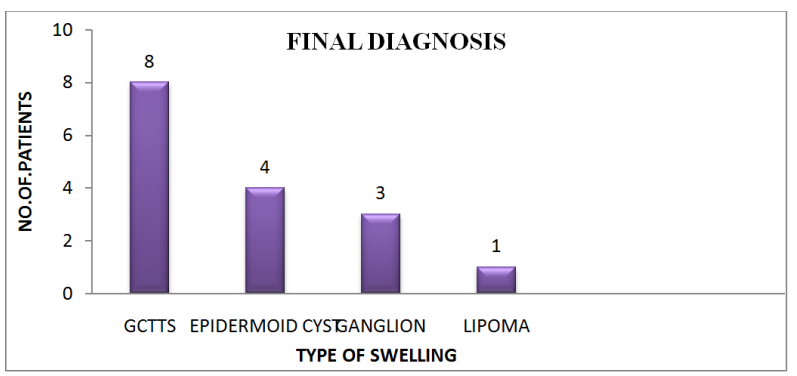

Figure 4. Final diagnosis.

Patients were followed for 1 year but none shown recurrence (Figure 4).

\section{Discussion}

In this study we have encountered some of the swellings which had similar clinical presentation of that of giant cell tumor of tendon sheath.

1) Ganglion cysts [3] are most common begnin tumors of hand and account $50 \%$ to $70 \%$ of benign tumors of hand. Usually seen at dorsal aspect of hand at base of fingers. They arise from the tissue which lines the joints or tendons and filled with gelatinous fluid.

2) Inclusion Epidermal cysts [4] it is also begnin occurs as a result of trauma. A penetrating injury drives epidermal elements deep into the soft tissues where they continue to grow and forms swelling. This forms a smooth, spherical swelling which is attached to the skin yet mobile over the underlying structures. Most cysts are found on the volar aspect of the hand, around the fingertips, but sometimes develop in surgical scars in the palm. They are usually painless but may attain a size that interferes with function. Cyst gets filled with cheesy substance that is attached to the undersurface of skin. In such cases surgical excision can be performed, but the entire cyst wall must be excised if recurrence is to be avoided.

3) Glomus tumor [5] is a rare benign condition that arises from the neuroarterial structure called glomus body, which accounts for $1 \%$ to $4.5 \%$ of tumors of hand. The normal glomus body is located in the stratum reticulare throughout the body but more concentrated in the digits. The average age of presentation is from 30 to 50 years. Clinically the mass is too small usually less than $7 \mathrm{~mm}$ in diameter and difficult to palpate. The swelling have point 
tenderness and temperature sensitivity. Although history and carefully performed physical examination significantly narrow the differential diagnosis, the plain radiographs are minimally helpful until the bony erosion occurs at the later stages of the disease and a complete excision usually leads to cure, with low incidence of recurrence.

4) Enchondroma [6] —Enchondroma is a solitary, benign, intramedullary cartilage tumor that is often found in the short tubular bones of the hands and feet, distal femur, and proximal humerus. The peak incidence is in the third decade and is equal between men and women. Most patients have no symptoms and found incidentally. Forceful hand activities may abruptly produce pain and swelling, as the weakened bone fractures. Radiographs demonstrate cortical thinning with slow expansion of bone. Curettage and bone graft is preferred in most cases.

5) Lipomas [7] - these are begnin, mesenchymal neoplasm's occurring in areas of abundant adipose tissue. They can be found anywhere in the body but very rare in fingers. They appear usually in $5^{\text {th }}$ and $6^{\text {th }}$ decade of life. These tumors are superficial arising from the subcutaneous tissues, clinically, usually asymptomatic, slow, growing, soft fluctuant and lobulated mobile mass. Limitation of mobility and impairment of grasping may be presenting symptoms. When arising around metacarpo-phalangeal joints lateral deviation of fingers may be seen.

6) Digital mucous cysts (DMCs) [4] are benign ganglion cysts of the digits, typically located at the distal interphalangeal (DIP) joints or in the proximal nail fold. Digital mucous cysts comprising $10 \%-15 \%$ of the total hand swellings. Women are affected more often than men. Digital mucous cysts most often are asymptomatic and benign. Pain can result from the impingement of cysts on adjacent nerve fibers. Larger cysts can disfigure the affected digit. Usually occur in the fifth to seventh decades. Usually solitary, round-to-oval shaped firm to fluctuant papulonodules. The cysts contain a viscous, gelatinous fluid that may be clear or yellow-tinged. The cysts are located off the midline of the digits and are more common on the radial than ulnar aspect of the fingers.

7) Rheumatoid nodules [8] are commonly seen overlying the olecranon at the elbow. However, these lesions can also occur at other pressure points in the pulps of the fingers and thumb. The nodules can be excised if they affect hand function, but they often recur.

8) Heberden's nodes and Bouchard's nodes [9] are hard swellings caused by formation of calcific spurs of the articular cartilage which can develop in the distal interphalangeal joints and proximal interphalangeal joints of fingers respectively of patients with osteoarthritis.

9) Gout [8] — this condition is characterised by hyperuricaemia and the deposition of monosodium urate crystals in the tissues (tophi). In the acute stage, this provokes an inflammatory reaction that may cause pain and swelling of the finger joints suggestive of an infective arthritis. Large tophi may occur in the pulps of the fingers in chronic cases. Management is usually conservative.

\section{Conclusion}

The purpose of this study is to establish a differential diagnosis between GCTTS and other soft tissue masses of fingers. Though ganglion is the most common begnin swelling which constitutes around $70 \%$ of all hand tumors followed by giant cell tumor (10\% - 15\%) and epidermoid cyst (3\% - 5\%) respectively [3], it is less common in fingers and in particular in flexor aspect. This study also states that diagnosis of giant cell tumor of tendon sheath is largely made by clinical examination but the other common swellings of fingers are to be ruled out which also present with similar features. FNAC can be a helpful tool for pre-operative pathological diagnosis of the swelling.

\section{References}

[1] Glowacki, K.A. (2003) Giant Cell Tumors of Tendon Sheath. Journal of the American Society for Surgery of Hand, 3 , 100-107. http://dx.doi.org/10.1016/S1531-0914(03)00025-1

[2] Garg, B. and Kotwal, P.P. (2011) Giant Cell Tumour of the Tendon Sheath of the Hand. Journal of Orthopaedic Surgery (Hong Kong), 19, 218-220.

[3] Oyle, R.W. (1946) Ganglia and Superficial Tumours. Practitiozzer, 156, 267.

[4] Woodburne, A.R. (1947) Myxomatous Degeneration Cysts of Skin and Subcutaneous Tissues. Archives of Dermatology and Syphiology, 56, 407. http://dx.doi.org/10.1001/archderm.1947.01520100003001

[5] Carroll, R.E. and Berman, A.T. (1972) Glomus Tumors of the Hand. Journal of Bone and Joint Surgery, 54A, 691703.

[6] Stack, H.G. (1964) Tumours of the Hand. Postgraduate Medical Journal, 40, 290-298. http://dx.doi.org/10.1136/pgmj.40.463.290

[7] Al Qattan, M.M., Al Lazzam, A.M. and Al Thunayan, A. (2005) Classification of Benign Fatty Tumours in the Upper 
Limb. Hand Surgery, 10, 43-59. http://dx.doi.org/10.1142/S0218810405002541

[8] Hasham, S. and Burke, F.D. (2007) Diagnosis and Treatment of Swellings in the Hand. Postgraduate Medical Journal, 83, 296-300. http://dx.doi.org/10.1136/pgmj.2005.043992

[9] Jay, V.V. (2000) The Legacy of William Heberden. Archives of Pathology \& Laboratory Medicine, $124,1751$. 
Scientific Research Publishing (SCIRP) is one of the largest Open Access journal publishers. It is currently publishing more than 200 open access, online, peer-reviewed journals covering a wide range of academic disciplines. SCIRP serves the worldwide academic communities and contributes to the progress and application of science with its publication.

Other selected journals from SCIRP are listed as below. Submit your manuscript to us via either submit@scirp.org or Online Submission Portal.
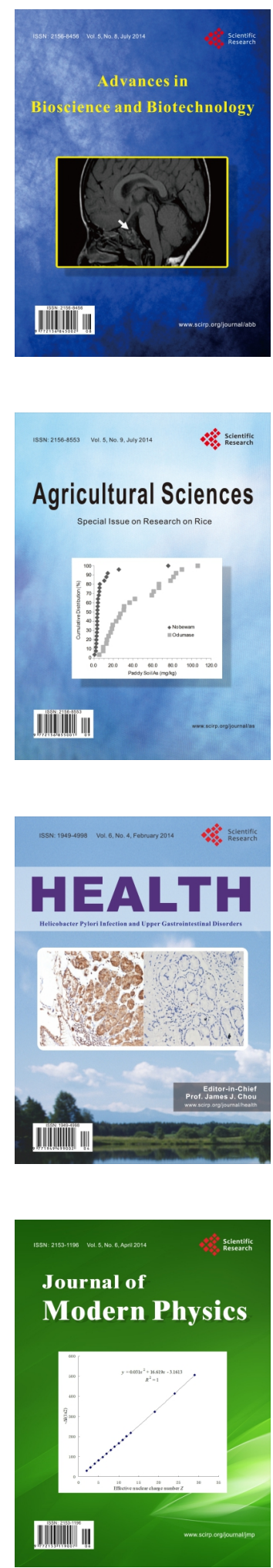
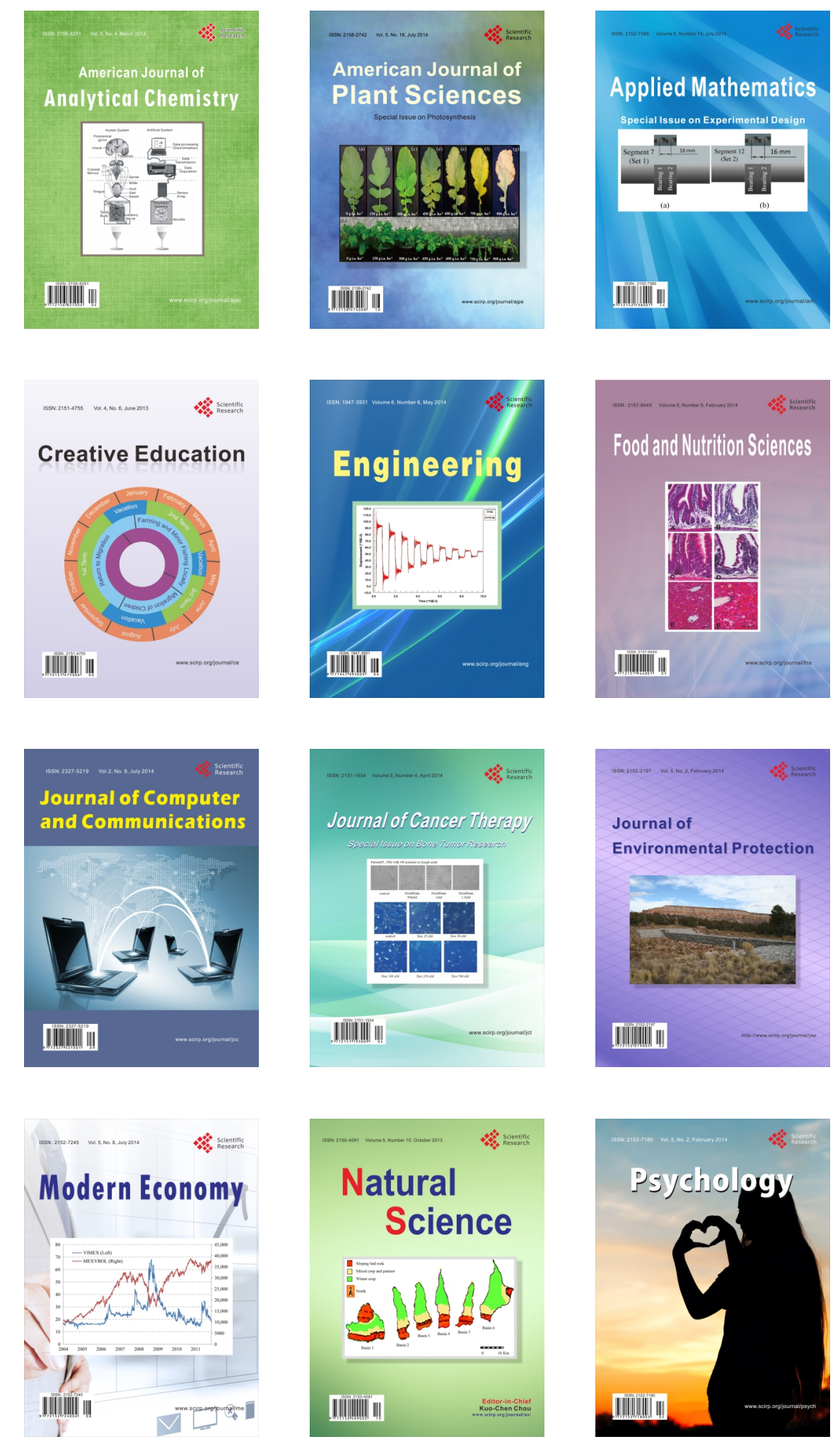